\title{
BMJ
}

\section{Prevalence of disease related prion protein in anonymous tonsil specimens in Britain: cross sectional opportunistic survey}

\author{
Jonathan P Clewley, clinical scientist,' Carole M Kelly, research epidemiologist, ${ }^{1}$ Nick Andrews, statistician, ${ }^{1}$ \\ Kelly Vogliqi, research technician, ${ }^{1}$ Gary Mallinson, clinical scientist, ${ }^{2}$ Maria Kaisar, research scientist,, ${ }^{2}$ David A \\ Hilton, consultant neuropathologist, ${ }^{3}$ James W Ironside, professor of clinical neuropathology, ${ }^{4}$ Philip Edwards, \\ biomedical scientist, ${ }^{3}$ Linda M McCardle, biomedical scientist, ${ }^{4}$ Diane L Ritchie, research assistant, ${ }^{4}$ Reza \\ Dabaghian, research scientist, ${ }^{1}$ Helen E Ambrose, research scientist, ${ }^{1}$ O Noel Gill, consultant epidemiologist ${ }^{1}$
}

${ }^{1}$ Centre for Infections, Health Protection Agency, London NW9 5EQ

${ }^{2}$ Bristol Institute for Transfusion Sciences, National Blood Service, Bristol BS10 5ND

${ }^{3}$ Department of Histopathology, Derriford Hospital, Plymouth PL6 8DH

${ }^{4}$ National CJD Surveillance Unit, University of Edinburgh, Western General Hospital, Edinburgh EH4 2XU

Correspondence to: JP Clewley jonathan.clewley@hpa.org.uk

Cite this as: $B M J$ 2009;338:b1442 doi:10.1136/bmj.b1442

\section{ABSTRACT}

Objective To establish with improved accuracy the prevalence of disease related prion protein $\left(\mathrm{Pr}^{\mathrm{C} I D}\right)$ in the population of Britain and thereby guide a proportionate public health response to limit the threat of healthcare associated transmission of variant Creutzfeldt-Jakob disease ( $v C J D)$.

Design Cross sectional opportunistic survey.

Study samples Anonymised tonsil pairs removed at elective tonsillectomy throughout England and Scotland. Setting National anonymous tissue archive for England and Scotland.

Main outcome measure Presence of $\mathrm{PrP}^{\mathrm{CJD}}$ determined by using two enzyme immunoassays based on different analytical principles, with further investigation by immunohistochemistry or immunoblotting of any samples reactive in either assay.

Results Testing of 63007 samples was completed by the end of September 2008. Of these, 12753 were from the birth cohort in which most VCJD cases have arisen (196185 ) and 19908 were from the 1986-95 cohort that would have been also exposed to bovine spongiform encephalopathy through infected meat or meat products. None of the samples tested was unequivocally reactive in both enzyme immunoassays. Only two samples were reactive in one or other enzyme immunoassay and equivocal in the other, and nine samples were equivocally reactive in both enzyme immunoassays. Two hundred and seventy six samples were initially reactive in one or other enzyme immunoassay; the repeat reactivity rate was $15 \%$ or less, depending on the enzyme immunoassay and cutoff definition. None of the samples (including all the 276 initially reactive in enzyme immunoassay) that were investigated by immunohistochemistry or immunoblotting was positive for the presence of $\operatorname{Pr} \mathrm{P}^{\mathrm{CID}}$. Conclusions The observed prevalence of $\mathrm{PrP}^{\mathrm{CJ} D}$ in tonsils from the 1961-95 combined birth cohort was 0/32 661 with a $95 \%$ confidence interval of 0 to 113 per million. In the $1961-85$ cohort, the prevalence of zero with a $95 \%$ confidence interval of 0 to 289 per million was lower than, but still consistent with, a previous survey of appendix tissue that showed a prevalence of 292 per million with a $95 \%$ confidence interval of 60 to 853 per million. Continuing to archive and test tonsil specimens, especially in older birth cohorts, and other complementary large scale anonymous tissue surveys, particularly of post-mortem tissues, will further refine the calculated prevalence of $\operatorname{PrP}^{\mathrm{CID}}$.

\section{INTRODUCTION}

Although the risk to the population of Britain of dietary exposure to the bovine spongiform encephalopathy agent that causes variant Creutzfeldt-Jakob disease (vCJD) has been virtually eliminated, the occurrence to date of four cases of $\mathrm{VCJD}$ infection resulting from blood transfusion has made real the threat of a secondary epidemic through healthcare associated human to human transmission. ${ }^{1-4}$ These cases from blood transfusion have also established the existence of an infective asymptomatic stage in human vCJD. Estimating the prevalence of this asymptomatic infective stage, although technically challenging, is essential to guide a proportionate public health response to reduce the risk of healthcare associated transmission.

Measurement of prevalence in the 1961-85 birth cohort is a priority, given that 138 of the 167 cases of vCJD to date in Britain have been in this group (with 39 cases in the 1961-9 and 99 in the 1970-85 birth cohorts). Data are available from previous analyses of appendix and tonsil specimens for the presence of disease related prion protein (designated $\operatorname{Pr} \mathrm{P}^{\mathrm{CJD}}$ ) by immunohistochemistry and immunoblotting. ${ }^{56}$ The first study screened 11247 appendix specimens and 1427 tonsil specimens by immunohistochemistry and found three positives in the appendixes from the 196185 birth cohort, giving a prevalence of 292 (95\% confidence interval 60 to 853 ) per million. ${ }^{5}$ A second study found no positives in 2000 tonsil specimens screened by both immunohistochemistry and immunoblotting; ${ }^{6}$ half of these tonsils were from patients aged over 
9 years and hence in the birth cohort likely to have had dietary exposure to bovine spongiform encephalopathy. Uncertainty about the true prevalence was increased when back calculation using plausible assumptions from the observed clinical vCJD cases suggested a much lower prevalence of sub-clinical vCJD infection than would be predicted from the finding of $\mathrm{PrP}^{\mathrm{CJD}}$ in three appendixes. ${ }^{57}$

The absence of a suitable blood test for $\operatorname{PrP}^{\mathrm{CJD}}$, and doubt about the clinical interpretation for a patient of a positive test result from testing any tissue, created major organisational and technical challenges for our large scale prevalence survey of $\operatorname{PrP}^{\mathrm{CJD}}$. To facilitate semi-automated enzyme immunoassay screening, we chose anonymised surgically removed tonsil pairs collected prospectively for the study reported here, rather than appendix tissue already archived in paraffin blocks that would have needed more labour intensive and slower immunohistochemical screening. $\operatorname{PrP}^{\mathrm{CJD}}$ is known to accumulate to relatively high levels in the tonsils of people with vCJD, although, because of the difficulty of identifying such cases, it has not yet been shown to be present pre-clinically. ${ }^{89}$

Commercially available enzyme immunoassay kits are routinely used for testing for bovine spongiform encephalopathy, scrapie, and other animal prion diseases; however, when our survey began no validated kits were available for testing human samples for $\operatorname{PrP}^{\mathrm{CJD}}$. We therefore issued a formal tender calling for manufacturers to take part in an enzyme immunoassay selection study and to supply suitable kits. The companies that responded were each sent two blinded panels of samples. Two assays, from Microsens and Bio-Rad, were able to detect brain from vCJD cases diluted $10^{-3}$ and spleen diluted $10^{-2}$ into tonsil homogenate (Jillian Cooper, personal communication), and we selected these for use in this study. We now report the results of testing of the first 63007 specimens from the intended collection of 100000 in a national anonymous tissue archive.

\section{METHODS}

\section{Test validation}

We obtained unfixed palatine tonsil samples from 32 sheep with scrapie and 10 that were uninfected, as well as aliquots of unfixed frozen tonsil tissue taken at autopsy from six patients who died of vCJD. We prepared 12\% homogenates from these and tested them by both enzyme immunoassays after making a dilution series from $10^{-1}$ to $10^{-5}$ with negative human tonsil homogenate. We used a panel of 250 human tonsils that had been previously tested and found to be negative by immunoblotting and immunohistochemistry as examples of "true" negative controls. ${ }^{6}$

\section{Survey tissue samples}

Paired tonsil samples from people of all ages, and from operations done between January 2004 and September 2008, were collected from hospitals throughout England and Scotland. One tonsil of the pair was collected as fresh tissue chilled to $4 \mathrm{C}$, and the other tonsil was collected in formalin. Tonsils arrived at the study centre an average of 65 (mode 50, median 113) hours after operation. Once transferred to suitable containers, samples were stored either at $-80 \mathrm{C}$ (fresh tissue) or at room temperature (fixed tissue).

Patients or their carers were given a leaflet explaining the aims of the study and that any result from testing their tonsil could not be traced back to them. An explicit paragraph and tick box to exercise a right to opt out of inclusion in the survey was included in the pre-tonsillectomy consent forms.

\section{Investigatory algorithm}

We homogenised a specimen of each tonsil pair and screened it with both enzyme immunoassays. We defined samples as "reactive," "high negative," or "negative" by a calculation based on the optical density readings from enzyme immunoassay for each microtitre plate. A reactive sample was within three standard deviations of the cut-off, and a high negative was within four standard deviations. We further investigated all samples that were initially reactive in either enzyme immunoassay or gave a high negative result in both enzyme immunoassays by immunoblotting and immunohistochemistry. We re-tested any sample that was high negative in one or other enzyme immunoassay by both enzyme immunoassays, and if it gave a reactive or high negative result in either we investigated it further by immunoblotting and immunohistochemistry. On occasion, we repeated immunoblotting tests with the same and with alternative antibodies.

\section{Definition of a positive result}

We defined a tonsil positive for $\mathrm{PrP}^{\mathrm{CJD}}$ as one identified by enzyme immunoassay that was immunohistochemistry positive, had the expected specific protein band pattern in immunoblotting, or both.

\section{RESULTS}

Test performance

At a dilution of $10^{-3}, 31$ of 32 scrapie sheep samples were reactive in both enzyme immunoassays, and at a $10^{-4}$ dilution 21 were reactive in the Microsens enzyme immunoassay and 16 were reactive in the Bio-Rad enzyme immunoassay. One positive sample was detectable only at a dilution of $10^{-1}$. Dilutions of $10^{-2}$ and $10^{-3}$ could be detected by immunoblotting.

The six tonsil aliquots from human vCJD cases varied in the amount of lymphoid germinal centre tissue that was present, as judged by visual inspection. Depending on the quality of the tissue, $\mathrm{PrP}^{\mathrm{CJD}}$ was detectable down to a dilution of $10^{-3}$ in the Microsens enzyme immunoassay and $10^{-2}$ in the Bio-Rad enzyme immunoassay (table 1). The amount of $\mathrm{PrP}^{\mathrm{CJD}}$ detected varied, as judged by the optical density values. This variation may have been due to biological differences in some cases, but an important contributory factor will have been the quality of the available tissue. Immunoblotting of aliquots of the vCJD samples showed that the expected specific band patterns of $\operatorname{PrP}^{\mathrm{CJD}}$ were 


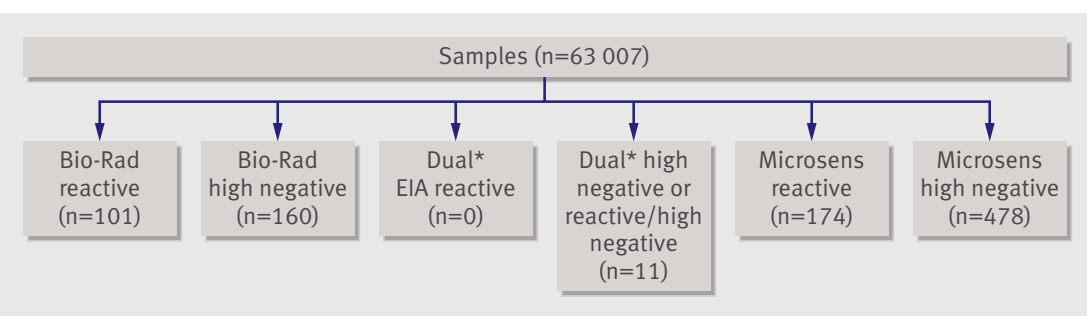

Enzyme immunoassay screening of human tonsil tissue homogenates for $\operatorname{PrP}^{\mathrm{CID}}{ }^{*}$ Dual enzyme immunoassay (EIA) reactive samples gave optical density readings above the cut-off classified as "reactive" in both Bio-Rad and Microsens tests; dual high negative or reactive/high negative samples gave optical density readings above the cut-off classified as "high negative" in both Bio-Rad and Microsens tests or was reactive in one and high negative in the other. All EIA reactive samples and most high negative samples were subject to both immunoblotting and immunohistochemistry testing (see text)

detectable. The sensitivities of the enzyme immunoassays were comparable to the immunoblotting results.

\section{Survey specimens collected}

Between January 2004 and October 2008, a total of 67696 tonsil pairs had been archived after collection from 134 hospital trusts throughout England and Scotland. We received forms without tonsil tissue for 1426 patients who objected and 762 in whom clinical pathology examination had been requested. All regions of England contributed samples, and 5651 came from Scotland between January 2006 and September 2008.

We also tested another 2015 anonymous specimens, from tonsillectomies done in the southeast of England between July 2000 and August 2002, of which half were from patients aged over 9 years at operation, and that were untested as part of an earlier survey. ${ }^{6}$

\begin{tabular}{|c|c|c|c|c|}
\hline \multirow[b]{2}{*}{ Dilution† } & \multicolumn{2}{|c|}{ Bio-Rad } & \multicolumn{2}{|c|}{ Microsens } \\
\hline & $\begin{array}{l}\text { Optical } \\
\text { density }\end{array}$ & Interpretation & $\begin{array}{l}\text { Optical } \\
\text { density }\end{array}$ & Interpretation \\
\hline \multicolumn{5}{|l|}{ Specimen 1: } \\
\hline Tonsil $10^{-2}$ & 0.06 & High negative & 0.12 & Reactive \\
\hline Brain $10^{-3}$ & 0.39 & Reactive & 0.08 & Reactive \\
\hline \multicolumn{5}{|l|}{ Specimen 2: } \\
\hline Tonsil $10^{-2}$ & 0.04 & Negative & 0.11 & Reactive \\
\hline \multicolumn{5}{|l|}{ Specimen 3: } \\
\hline Tonsil $10^{-2}$ & 0.06 & High negative & 0.20 & Reactive \\
\hline \multicolumn{5}{|l|}{ Specimen 4: } \\
\hline Tonsil $10^{-1}$ & 0.04 & Negative & 0.10 & Reactive \\
\hline \multicolumn{5}{|l|}{ Specimen 5: } \\
\hline Tonsil $10^{-3}$ & 0.04 & Negative & 0.09 & Reactive \\
\hline \multicolumn{5}{|l|}{ Specimen 6: } \\
\hline Tonsil $10^{-1}$ & 0.13 & Reactive & 0.21 & Reactive \\
\hline
\end{tabular}

*Three specimens supplied by National CJD Surveillance Unit (including paired tonsil and brain) and three by MRC Prion Unit.

†Dilution from $12 \%$ homogenate $\left(10^{0}\right) ; 10^{-1}$ dilution is therefore equivalent to $0.012 \mathrm{~g} / \mathrm{ml} \mathrm{vCJD}$ tonsil tissue homogenate; as dilution is in negative homogenate, total tissue concentration was $0.12 \mathrm{~g} / \mathrm{ml}$ for all samples tested.

\section{Enzyme immunoassay screening results}

By the end of September 2008, we had screened 63007 samples with both enzyme immunoassays and, where indicated, completed investigatory testing (figure).

In one or other of the enzyme immunoassays, 276 samples gave an optical density defined as reactive and 638 were classed as high negative (figure). To define the repeat reactivity rate by enzyme immunoassay, we retested 487 reactive and high negative samples by enzyme immunoassay at the beginning of the project, before immunohistochemistry and immunoblotting confirmatory testing. The repeat reactivity rate was $15 \%(7 / 48)$ for the initially reactive samples and $3.5 \%(4 / 116)$ for the initially high negative samples in the Bio-Rad enzyme immunoassay. The equivalent figures for the Microsens enzyme immunoassay were $12 \%(7 / 60)$ and $10 \%(26 / 263)$. All initially reactive samples and any initially high negative samples that gave a repeat reactive or high negative result by enzyme immunoassay were subject to immunohistochemistry and immunoblotting confirmatory testing. Any samples that were initially reactive or high negative but which were not repeat tested by enzyme immunoassay went directly for immunohistochemistry and immunoblotting (figure).

No samples were clearly reactive in both enzyme immunoassays. One was reactive by Microsens and high negative by Bio-Rad, and another was reactive by Bio-Rad and high negative by Microsens. Nine were high negative by both the Microsens and BioRad enzyme immunoassays. Seven of these 11 samples were methionine homozygote at codon 129 of the prion protein gene (PRNP) and four were heterozygote; only four (three homozygote and one heterozygote) were from people born before 1996 and therefore likely to have had dietary exposure to bovine spongiform encephalopathy.

\section{Immunoblotting results}

We demonstrated satisfactory immunoblotting performance, using two different protocols in two separate laboratories, by testing the tonsil tissue taken at autopsy from vCJD patients, as well as by spiking experiments using scrapie sheep tonsil tissue, scrapie infected hamster brain, and human vCJD brain tissue.

None of the survey sub-sample investigated by immunoblotting gave a protein banding pattern consistent with the presence of $\operatorname{PrP}^{\mathrm{CJD}}$. Some samples that showed a single band, which was not consistent with any expected pattern, were re-tested by immunoblotting either with the same antibody or with different antibodies, including 3F4 and a secondary antibody designed to reveal non-specific antibody interactions. Only one sample still showed a single immunoblotting band; it was methionine homozygote at codon 129 and from a patient in the 1986-90 birth cohort, and it was negative by immunohistochemistry.

\section{Immunohistochemistry results}

More than 800 tonsils, selected on the basis of the enzyme immunoassay results, have been investigated 
by immunohistochemistry in one or other of two experienced laboratories, and none was scored positive for $\operatorname{PrP}^{\mathrm{CJD}}$.

\section{Prevalence estimates}

Overall, $32661(52 \%)$ of the 63007 samples tested came from people born in 1995 or earlier who were alive at the time when bovine spongiform encephalopathy contaminated meat was being consumed (table 2). The observed prevalence of $\mathrm{PrP}^{\mathrm{CJD}}$ in this group was zero (95\% confidence interval 0 to 113 per million). Combining the 1986-90 and 1991-5 cohorts gave a prevalence of zero with an upper $95 \%$ confidence limit of 185 per million. The prevalence in the combined 1996-2000 and 2001-7 unexposed cohorts was also zero with an upper $95 \%$ confidence limit of 122 per million.

Although the zero per million prevalence seen in the 1961-85 cohort (upper 95\% confidence limit 289 per million) was different from the 292 per million (95\% confidence interval 60 to 853 per million) found in the earlier survey of appendix tissue, ${ }^{5}$ the $95 \%$ confidence intervals for both surveys overlapped (a formal comparison of the prevalence estimates gives a $\mathrm{P}$ value of 0.09$)$.

\section{DISCUSSION}

Initial results from testing the tonsil specimens in a national anonymous tissue archive have shown the prevalence of $\mathrm{PrP}^{\mathrm{CJD}}$ to be zero in 63007 overall and zero in 12753 in the birth cohort in Britain in which most cases of vCJD have occurred. Interpretation of this finding, and of the difference between it and the earlier survey of appendix tissue, depends critically on three factors: the sensitivity of the test system chosen to screen the tonsil specimens, the representativeness of the sample specimens of the people most vulnerable to vCJD disease, and the natural history of the infectivity of bovine spongiform encephalopathy in individual patients, particularly the time when $\mathrm{PrP}^{\mathrm{CJD}}$ first appears pre-clinically in tonsil compared with appendix tissue and how long it persists.

Table $2 \mid$ Prevalence of disease related prion protein $\left(\mathrm{PrP}^{\mathrm{CID}}\right)$ in Britain by birth cohort (positive/total; rate per million with $95 \%$ confidence intervals*)

\begin{tabular}{lccc} 
& Current (2004-September 2008) & \multicolumn{2}{c}{ Earliert (1995-9) } \\
\cline { 3 - 4 } Birth cohort & national tissue survey: tonsils & Appendices & Tonsils \\
\cline { 3 - 4 } 1940 and before & NA & NA & $0 / 573$ \\
\hline $1941-60$ & $0 / 12753 ; 0(0$ to 289$)$ & $3 / 10278 ; 292(60$ to 853$)$ & $0 / 225$ \\
\hline $1961-85$ & $0 / 9564 ; 0(0$ to 386$)$ & $0 / 396$ & $0 / 266$ \\
\hline $1986-90$ & $0 / 10344 ; 0(0$ to 357$)$ & NA & $0 / 119$ \\
\hline $1991-5$ & $0 / 15708 ; 0(0$ to 253$)$ & NA & $0 / 106$ \\
\hline $1996-2000$ & $0 / 14638 ; 0(0$ to 252$)$ & NA & $0 / 17$ \\
\hline $2001-7$ & $0 / 63007 ; 0(0$ to 59$)$ & $3 / 11247 ; 267(55$ to 779$)$ & $0 / 1427 ; 0(0$ to 2 \\
\hline Total & & & NA \\
\hline
\end{tabular}

$\mathrm{NA}=$ not available

*95\% confidence interval calculated only when denominator exceeds 1000 .

†Data from separate tissue survey of 2000 tonsils (July 2000-August 2002) in southeast England (including London) ${ }^{6}$ not included.

\section{Test sensitivity}

Three experiments investigated the sensitivity of the enzyme immunoassays. The first was the enzyme immunoassay selection study, the second was the interrogation of the enzyme immunoassays with tonsil tissue from sheep with scrapie, and the third was the use of tonsil tissue from patients who died from vCJD. Overall, these indicated that the Microsens enzyme immunoassay was more sensitive than the Bio-Rad enzyme immunoassay for detection of $\mathrm{PrP}^{\mathrm{CJD}}$ in lymphatic tissue. The most sensitive detection was by the Microsens enzyme immunoassay with a sample containing $12 \mu \mathrm{g}$ vCJD tonsil tissue; the equivalent for the Bio-Rad enzyme immunoassay was $480 \mu \mathrm{g}$ vCJD tonsil tissue (table 1). When used for screening, 12000 $\mu \mathrm{g}$ tonsil tissue was applied to the Microsens enzyme immunoassay and $48000 \mu \mathrm{g}$ to the Bio-Rad enzyme immunoassay. Therefore, the two enzyme immunoassays should have been sufficiently sensitive to detect $\mathrm{PrP}^{\mathrm{CJD}}$ in tonsils from asymptomatic people incubating vCJD if levels of $\mathrm{PrP}^{\mathrm{CJD}}$ were a 10th to a 1000th of those in patients with symptoms.

The dual enzyme immunoassay tonsil screening protocol may be at least as sensitive as any other large scale testing for abnormal prion protein that could have been used. The enzyme immunoassays use different test principles and antibodies, perhaps reinforcing the sensitivity of each. Reading of the results was automated, and we used a range of controls on each 96 well plate of tests. We deemed the use of a single enzyme immunoassay cut-off value as commonly applied to screen a population with many positives to be inappropriate, as this particular set of samples was expected (and found) to be overwhelmingly negative. Therefore, we calculated the cut-off value for each plate individually, and this method almost doubled the number of specimens that were selected for further investigation by immunoblotting and immunohistochemistry.

Several reasons exist why a specimen could have given a false high (reactive or high negative) optical density reading in either or both enzyme immunoassays: inadequate proteinase $\mathrm{K}$ digestion of $\mathrm{PrP}^{\mathrm{C}}$ (the normal cellular form of PrP) for the Bio-Rad enzyme immunoassay, inadequate removal of $\mathrm{PrP}^{\mathrm{C}}$ bound to the capture polyanion for the Microsens enzyme immunoassay, non-specific antibody interactions owing to the high antibody concentration in tonsil tissue, and poor sample quality or technical failures. Therefore, applying more specific immunoblotting and immunohistochemistry tests to confirm whether $\mathrm{PrP}^{\mathrm{CJD}}$ was present was essential.

In comparison with immunohistochemistry, the volume of tonsil tissue screened by enzyme immunoassay was relatively large. Immunohistochemistry on appendix tissue may also be less specific than immunoblotting, so that prevalence estimated by immunohistochemistry screening may tend to overestimate the true situation. ${ }^{9}$ However, to tackle the lingering uncertainty that screening immunohistochemistry might be more sensitive than dual enzyme immunoassay 
screening, a further study to re-test 10000 of the archived tonsils by immunohistochemistry has been commissioned. These 10000 samples comprise those from patients in the 1961-85 birth cohort, as well as any samples that gave optical density readings above the cut-offs in either of the two enzyme immunoassays. The results from this major undertaking should be available some time during 2009.

Two of the three positive samples in the retrospective immunohistochemistry study of appendix tissue were valine homozygous at codon 129 of $P R N P^{510}$ Therefore, we can be confident that the antibodies used in our immunohistochemistry analysis would have showed $\mathrm{PrP}^{\mathrm{CJD}}$ in a valine homozygote if it was present. The antibodies used in the enzyme immunoassay and immunoblotting would similarly be likely to detect $\mathrm{PrP}^{\mathrm{CJD}}$ in a valine homozygote and, by extension, $\mathrm{PrP}^{\mathrm{CJD}}$ in a heterozygote. Although the immunoblotting profiles of valine homozygote and heterozygote vCJD are unknown, they may be expected to consist of three or four glycoforms. ${ }^{11}$ The immunoblotting profile of the spleen in a case of asymptomatic vCJD infection in a heterozygote patient showed similarities to that in clinical vCJD spleen samples in methionine homozygote patients, with a predominance of the diglycosylated band. ${ }^{2} \mathrm{We}$ did not observe by immunoblotting any pattern similar to any recognised profiles in sporadic CJD or vCJD. ${ }^{12-16}$ The only repeatedly anomalous immunoblotting pattern seen was of a single immunoblotting band in an immunohistochemistry negative sample, which was methionine homozygote at codon 129 of PRNP.

\section{Representativeness of sample}

The age and sex characteristics of the samples in our study reflected the current age and sex distribution of people having tonsillectomy: $72 \%$ of those born in 1995 or earlier in our survey were female, compared with $48 \%$ of those born since 1995 . Although only $44 \%$ of vCJD cases to date have been in women, we do not think that the predominance of females in our older sample of tonsils could have biased our findings with respect to prevalence of $\mathrm{PrP}^{\mathrm{CJD}}$.

Given the very strong association between PrPCJD and people who are homozygous for methionine at PRNP codon $129,{ }^{5}$ it is important to note that our sample was likely to have been representative of this genetic susceptibility: an analysis of 466 of the tonsils in our survey showed $47 \%$ to be methionine homozygotes at codon 129, consistent with what was expected..$^{10-20}$ Therefore, of the 32661 tonsils tested from people born before 1996, approximately 15351 $(47 \%)$ would have been from methionine homozygotes.

Several differences must be considered when comparing results between surveys. First and foremost is that previously appendix tissues were screened by immunohistochemistry, whereas we screened tonsil tissue by enzyme immunoassay. Secondly, an average of 10 years elapsed between when the previous large sample from the 1961-85 birth cohort had their appendixes removed (during 1995-9) until our sample had their tonsils removed (mostly in 2006-7) - 10 years during which abnormal prion protein levels might be expected to have increased rather than diminished. Within this birth cohort, however, the average age of appendicectomy was estimated to be four years older than the average age of tonsillectomy, so the average duration of the opportunity for $\operatorname{PrP}^{\mathrm{CJD}}$ to increase between the appendicectomy samples and the tonsillectomy samples would have been about six years. On the other hand, the relatively older appendix sample that was collected earlier may conceivably have contained a wave of infectivity in the 1961-85 cohort of the British population that was not present in the younger tonsil group that was sampled later.

Detailed information on previous operative history was sought on every vCJD case diagnosed in Britain. Seventeen of 167 patients were reported to have had tonsillectomy; 14 of these were in the 1961-85 birth cohort, and the remaining three were in the pre-1960 birth cohort. None was likely to have had specimens included in this or the earlier tonsil survey (Hester Ward, personal communication). ${ }^{6}$

\section{Natural history}

While PrP ${ }^{\mathrm{CJD}}$ has been found consistently by immunoblotting and immunohistochemistry in tonsil tissue from patients with vCJD ${ }^{8921-24} \mathrm{PrP}^{\mathrm{CJD}}$ in a tonsil from an asymptomatic person has yet to be reported. Given, however, that tonsillar tissue has been shown to accumulate $\mathrm{PrP}^{\mathrm{Sc}}$ before the onset of clinical disease in nonhuman primates and well before the onset of clinical disease in sheep experimentally infected orally with bovine spongiform encephalopathy ${ }^{2526}$ we considered tonsil tissue to be a reliable substrate for a survey of prevalence in humans. Also, the use of fresh tonsil tissue allowed more comprehensive laboratory testing, if necessary, after the initial screening assays.

$\mathrm{PrP}^{\mathrm{CJD}}$ has been observed to accumulate in appendix tissue in vCJD (19/20 positive/tested $)^{92728}$ and, in two cases, before symptoms developed. ${ }^{29}{ }^{30}$ However, data on the timing of the appearance of $\mathrm{PrP}^{\mathrm{CJD}}$ in different peripheral lymphoreticular tissues during the prolonged incubation period of $\mathrm{vCJD}$ are sparse. The rate of accumulation of $\mathrm{PrP}^{\mathrm{CJD}}$ in tonsil and appendix tissue could differ such that the findings of surveys of appendix and tonsil tissues would also differ. The positive samples found in the appendix survey presumably came from people who were infected a relatively short time earlier, during the peak of the bovine spongiform encephalopathy epidemic. ${ }^{5}$ Moreover, should the incubation period for prion disease be considerably longer in people with different genotypes, uncertainty about the timing of the appearance of detectable PrP $\mathrm{PJD}^{\mathrm{D}}$ in these will increase, with concomitant implications for the interpretation of results of $\operatorname{PrP}^{C J D}$ prevalence surveys.

Animal experiments have shown that high infectivity, and indeed disease, can be present in the absence of detectable proteinase $\mathrm{K}$ resistant $\mathrm{PrP}^{\mathrm{Sc}} .{ }^{31}$ The extent to 


\section{WHAT IS ALREADY KNOWN ON THIS TOPIC}

Statistical back calculation based on cases of vCJD to 2004 has given estimates of between 10 and 190 further clinical cases over the next few decades

A study of archived appendix and tonsil tissues found a prevalence of lymphoreticular accumulation of pathogenic prion protein consistent with the existence of between 520 and 13000 sub-clinical cases

Therefore, a discrepancy exists between estimates, which needs to be resolved to ensure that proportionate public health measures are implemented

\section{WHAT THIS STUDY ADDS}

Testing of tissue from more than 63000 tonsils, of which 12763 were from the 1961-85 birth cohort, has not shown evidence for the presence of the pathogenic form of the prion protein

The prevalence of sub-clinical VCJD infection in Britain may be lower than that given by previous estimates, with an upper limit of 289 per million in the 1961-85 birth cohort

which this observation can be generalised is, however, unclear, as $\operatorname{PrP}^{\mathrm{CJD}}$ has been shown to be present in the lymphoid tissues of all vCJD patients tested ${ }^{927}$ If other, more reliable, indicators of vCJD become available, screening the existing samples with tests for these markers, and thereby determining whether any vCJD positives have been missed by looking only for $\mathrm{PrP}^{\mathrm{CJD}}$, may be possible.

Data from animal experiments also show "clearance" of abnormal prion protein after inoculation. ${ }^{3132}$ Therefore, the abnormal prion protein found in the earlier survey of appendix tissue may conceivably have been transient and eventually cleared without leading to disease, so that the appendix survey result would not have been replicated by the later tonsil survey.

\section{Conclusion}

We tested more than 32000 tonsils from people in the age range most exposed to meat contaminated with bovine spongiform encephalopathy, and believed to be asymptomatic when sampled, for disease related prion protein. Using two sensitive enzyme immunoassays, with selective application of specific immunoblotting and immunohistochemistry techniques, we found no samples positive for $\mathrm{PrP}^{\mathrm{CJD}}$, a prevalence of 0 per million (with an upper 95\% confidence limit of 113 per million). For the 1961-85 birth cohort, the prevalence of zero with a $95 \%$ confidence interval of 0 to 289 per million was lower than, but still consistent with, the earlier study of appendix tissue (60 to 853 per million). A $\mathrm{P}$ value of 0.09 applies to the comparison of the two prevalence estimates. These two surveys may not, however, be directly comparable owing to differences in testing methods, tissues sampled, and the time the tissues were removed (typically about 10 years earlier in the previous study). More data are needed through continuing the testing of tonsils from people born before 1996, despite the low frequency of tonsillectomy in older birth cohorts. In addition, creation and testing of other anonymous tissue archives, such as one based on coronial autopsies, or a repeat of the appendix survey on an even larger scale, should provide a larger sample set of the people most exposed to the bovine spongiform encephalopathy agent. ${ }^{33}$

We thank Chris Kelly, Sally Hayes, Jahnavi Joshi, Tom Turner, and Lisa Walker for laboratory testing; Caroline Lawson for administrative help; Philip P Mortimer and David W G Brown for advice; Colin Southwell for help with the tender process; Philip Minor and Jillian Cooper of the National Institute for Biological Standards and Control for collaboration on the initial validation studies; Alan Hill for help with Excel programs; Peter Horby, Frankie Lever, and Anna Molesworth for initial work establishing the national anonymous tissue archive; Rosemary Baugh for assistance with the immunohistochemistry in Plymouth; Suzanne Lowrie and Margaret LeGrice for assistance with the immunohistochemistry in Edinburgh; all the ENT consultants, pre-assessment nurses, theatre staff, and pathologist collaborators at 134 hospitals; Michelle Clarke, Johanna Reilly, and Joan Sneddon at Health Protection Scotland; Hester Ward and Mark Head at the National CJD Surveillance Unit; Neil Raven and Joanne George for the provision of a brain from a hamster infected with scrapie: Danny Matthews and Sue Bellworthy of the Veterinary Laboratories Agency's TSE Archive for provision of tonsil tissue from sheep with scrapie and from uninfected sheep; Jonathan D F Wadsworth and John Collinge at the MRC Prion Unit for providing control negative tonsils and 3000 untested tonsils, and vCJD tonsil and brain samples.

This study was originally proposed by a Medical Research Council and Department of Health committee. It was overseen by an Expert Advisory Group on the Laboratory Testing Strategy for Large Scale Abnormal Prion Prevalence Studies with a membership of N Andrews, D W G Brown, J P Clewley, J Cooper, R Eglin, E Gadd, O N Gill, M Head, D A Hilton, J W Ironside, G Jackson, C M Kelly, G Mallinson, D Matthews, P Minor (chair), P P Mortimer, N Raven, J R Stephenson, and J D F Wadsworth. Data from this anonymous tonsil survey were discussed in public at meetings of the Spongiform Encephalopathy Advisory Committee (www seac.gov.uk) in December 2007 and April 2008; and see a statement issued in August 2008 (www.seac.gov.uk/statements/state-cjdinfections.pdf).

Contributors: JPC designed and analysed the laboratory studies and wrote the paper with ONG, who initiated the study and did clinical and epidemiological analyses. CMK recruited hospitals to the study and did epidemiological analyses. NA did statistical and epidemiological analyses. KV organised the National Anonymous Tissue Archive laboratory, tonsil processing, and enzyme immunoassay testing. GM, MK, and RD did the immunoblotting. DAH, PE, JWI, LMCC, and DLR did the immunohistochemistry. JWI provided some of the VCJD clinical tissue used in the work. HEA did the codon 129 genotyping. JPC and ONG are the guarantors.

Funding: The study was funded by the Department of Health; the work was carried out independently of the funder.

Competing interests: None declared.

Ethical approval: The study received ethical approval from the Trent Multi-centre Research Ethics Committee (MREC/03/4/073). None of the participants in the study was subsequently identifiable.

1 Llewelyn CA, Hewitt PE, Knight RS, Amar K, Cousens S, Mackenzie I, et al. Possible transmission of variant Creutzfeldt-Jakob disease by blood transfusion. Lancet 2004;363:417-21.

2 Peden AH, Head MW, Ritchie DL, Bell JE, Ironside JW. Preclinical vCJD after blood transfusion in a PRNP codon 129 heterozygous patient. Lancet 2004;364:527-9.

3 Wroe SJ, Pal S, Siddique D, Hyare H, Macfarlane R, Joiner S, et al. Clinical presentation and pre-mortem diagnosis of variant Creutzfeldt-Jakob disease associated with blood transfusion: a case report. Lancet 2006;368:2061-7.

4 Fourth case of transfusion-associated variant-CJD infection. Health Prot Rep 2007;1.

5 Hilton DA, Ghani AC, Conyers L, Edwards P, McCardle L, Ritchie D, et al. Prevalence of lymphoreticular prion protein accumulation in UK tissue samples. J Pathol 2004;203:733-9.

6 Frosh A, Smith LC, Jackson CJ, Linehan JM, Brandner S, Wadsworth JDF, et al. Analysis of 2000 consecutive UK tonsillectomy specimens for disease-related prion protein. Lancet 2004;364:1260-2.

7 Clarke P, Ghani Azra C. Projections of the future course of the primary VCJD epidemic in the UK: inclusion of subclinical infection and the possibility of wider genetic susceptibility. J R Soc Interface 2005;2:19-31.

8 Hill AF, Butterworth RJ, Joiner S, Jackson G, Rossor MN, Thomas DJ, et al. Investigation of variant Creutzfeldt-Jakob disease and other human prion diseases with tonsil biopsy samples. Lancet 1999;353:183-9. 
9 Wadsworth JD, Joiner S, Hill AF, Campbell TA, Desbruslais M, Luthert PJ, et al. Tissue distribution of protease resistant prion protein in variant Creutzfeldt-Jakob disease using a highly sensitive immunoblotting assay. Lancet 2001;358:171-80.

10 Ironside JW, Bishop MT, Connolly K, Hegazy D, Lowrie S, Le Grice M, et al. Variant Creutzfeldt-Jakob disease: prion protein genotype analysis of positive appendix tissue samples from a retrospective prevalence study. BMJ 2006;332:1186-8.

11 Head MW, Bunn TJR, Bishop MT, McLoughlin V, Lowrie S, McKimmie CS, et al. Prion protein heterogeneity in sporadic but not variant Creutzfeldt-Jakob disease: UK cases 1991-2002. Ann Neurol 2004;55:851-9.

12 Hill AF, Joiner S, Wadsworth JD, Sidle KC, Bell JE, Budka H, et al. Molecular classification of sporadic Creutzfeldt-Jakob disease. Brain 2003;126:1333-46.

13 Wadsworth JD, Hill AF, Beck JA, Collinge J. Molecular and clinical classification of human prion disease. Br Med Bull 2003;66:241-54.

14 Schoch G, Seeger H, Bogousslavsky J, Tolnay M, Janzer RC, Aguzzi A, et al. Analysis of prion strains by PrPSc profiling in sporadic Creutzfeldt-Jakob Disease. PLoS Medicine 2006;3:e14.

15 Cali I, Castellani R, Yuan J, Al Shekhlee A, Cohen ML, Xiao X, et al. Classification of sporadic Creutzfeldt-Jakob disease revisited. Brain 2006;129:2266-77.

16 Yull HM, Ritchie DL, Langeveld JPM, van Zijderveld FG, Bruce ME, Ironside JW, et al. Detection of type 1 prion protein in variant Creutzfeldt-Jakob disease. Am J Pathol 2006;168:151-7.

17 Palmer MS, Dryden AJ, Hughes JT, Collinge J. Homozygous prion protein genotype predisposes to sporadic Creutzfeldt-Jakob disease. Nature 1991;352:340-2.

18 Mead S, Stumpf MPH, Whitfield J, Beck JA, Poulter M, Campbell T, et al. Balancing selection at the prion protein gene consistent with prehistoric kurulike epidemics. Science 2003;300:640-3.

19 Schulz-Schaeffer WJ, Giese A, Windl O, Kretzschmar HA. Polymorphism at codon 129 of the prion protein gene determines cerebellar pathology in Creutzfeldt-Jakob disease. Clin Neuropatho 1996;15:353-7.

20 Zimmermann K, Turecek PL, Schwarz HP. Genotyping of the prion protein gene at codon 129. Acta Neuropathol 1999;97:355-8.

21 Chazot G, Broussolle E, Lapras C, Blattler T, Aguzzi A, Kopp N. New variant of Creutzfeldt-Jakob disease in a 26-year-old French man. Lancet 1996;347:1181.

22 Hill AF, Zeidler M, Ironside J, Collinge J. Diagnosis of new variant Creutzfeldt-Jakob disease by tonsil biopsy. Lancet 1997;349:99-100.
23 Bruce ME, McConnell I, Will RG, Ironside JW. Detection of variant Creutzfeldt-Jakob disease infectivity in extraneural tissues. Lancet 2001;358:208-9.

24 Ironside JW, McCardle L, Horsburgh A, Lim Z, Head MW. Pathological diagnosis of variant Creutzfeldt-Jakob disease. APMIS 2002;110:79-87.

25 Bons N, Mestre-Frances N, Belli P, Cathala F, Gajdusek DC, Brown P. Natural and experimental oral infection of nonhuman primates by bovine spongiform encephalopathy agents. Proc Natl Acad Sci USA 1999;96:4046-51.

26 Van Keulen LJ, Vromans ME, Dolstra CH, Bossers A, van Zijderveld FG. Pathogenesis of bovine spongiform encephalopathy in sheep. Arch Virol Suppl 2008;153:445-53.

27 Head MW, Ritchie D, Smith N, McLoughlin V, Nailon W, Samad S, et al. Peripheral tissue involvement in sporadic, iatrogenic, and variant Creutzfeldt-Jakob disease: an immunohistochemical, quantitative, and biochemical study. Am J Pathol 2004;164:143-53.

28 Joiner S, Linehan J, Brandner S, Wadsworth JDF, Collinge J. Irregular presence of abnormal prion protein in appendix in variant Creutzfeldt-Jakob disease. J Neurol Neurosurg Psychiatry 2002;73:597-8

29 Hilton DA, Sutak J, Smith MEF, Penney M, Conyers L, Edwards P, et al. Specificity of lymphoreticular accumulation of prion protein for variant Creutzfeldt-Jakob disease. J Clin Pathol 2004;57:300-2.

30 Hilton DA, Fathers E, Edwards P, Ironside JW, Zaijcek J. Prion immunoreactivity in appendix before clinical onset of variant Creutzfeldt-Jakob disease. Lancet 1998;352:703-4.

31 Barron RM, Campbell SL, King D, Bellon A, Chapman KE, Williamson RA, et al. High titres of transmissible spongiform encephalopathy infectivity associated with extremely low levels of PrPSc in vivo. J Biol Chem 2007;282:35878-86.

32 Safar JG, DeArmond SJ, Kociuba K, Deering C, Didorenko S, Bouzamondo-Bernstein E, et al. Prion clearance in bigenic mice. Gen Virol 2005;86:2913-23.

33 Montgomery J, chairman. A national human post-mortem tissue archive to study the prevalence of abnormal prion protein: recommendations of a working group; presented to the ChiefMedical Officer, May 2007 (available at www.hpa.org.uk/web/HPAwebFile/ HPAweb_C/1240986155624).

Accepted: 15 December 2008 